\title{
Experimental investigation of gas kick effects on dynamic drilling parameters
}

\author{
Idris O. Sule ${ }^{1,2} \cdot$ Faisal Khan ${ }^{1} \cdot$ Stephen Butt ${ }^{2}$
}

Received: 26 September 2017 / Accepted: 17 June 2018 / Published online: 25 June 2018

(c) The Author(s) 2018

\begin{abstract}
Blowout incidents not only lead to fatalities but also cause loss of assets, expensive clean-up, costly incident investigations and reports, and negative impact on the environment. The 2010 Macondo blowout accident in the Gulf of Mexico was an eye-opener for many oil and gas operators and oilfield service companies; thus, making early kick detection technology research one of the top industry agendas. However, only limited progress has been made in detection technologies that focus on downhole parameters due to the complexity of offshore drilling operations that is increasingly shifting towards the deepwater. Therefore, the current paper experimentally explores downhole drilling parameters for kick indication during drilling. The study utilizes a fully instrumented laboratory scale drilling rig coupled with an air injection and surface monitoring systems. This study observed a sudden jump in bottomhole pressure, increased volume of the return fluid, decreased density of the return fluid, reduced rate of penetration, and increased rotary speed as indicators of kick. The most significant new finding, which is also validated with field reports, is the dampening effects of the drilling vibrations due to kick. Frequency analysis of the axial bit-rock displacements/vibrations confirms the changes of frequencies due to kick induction during drilling. Coupling this important finding with dynamic drilling models, the response of the drilling system at surface (e.g. standpipe, choke pressures, etc.) indicating this change can be predicted.
\end{abstract}

Keywords Kick indicators · Drilling $\cdot$ Axial bit vibrations $\cdot$ Early kick detection

\section{Introduction}

Early kick detection (EKD) is a vital component of well control system. The prevention or management of kicks and/ or fluid loss occurrence during drilling operations is crucial, particularly in deepwater drilling activities due to the complexity of equipment and operations. Well control failure occurrences could typically cost the oil and gas industry billions of dollars in a year due to non-productive time (NPT) and/or blowout incident, and affect the safety of drilling personnel. In addition to the complex operation involved

Idris O. Sule

W07ios@mun.ca

1 Centre for Risk, Integrity and Safety Engineering (C-RISE), Process Engineering Department, Faculty of Engineering and Applied Science, Memorial University, St. John's, NL, Canada

2 Drilling Technology Laboratory (DTL), Process Engineering Department, Faculty of Engineering and Applied Science, Memorial University, St. John's, NL, Canada with deepwater drilling, many deepwater wells have greater depths and narrow pressure margins between pore pressure and fracture gradient, which heighten the risk of unexpected events such as kick or fluid loss. Given the extent of these challenging drilling operations coupled with today's low oil and gas prices, oil and gas operators are continually striving to improve not only the drilling efficiency but also to understand the behaviour of downhole fluid to survive and grow.

Blowouts can be disastrous, expensive, and cause fatalities; a good example was the dramatic BP Deepwater Horizon blowout in 2010. Several investigative reports indicate a need for more sophisticated EKD technologies among other root causes (Graham et al. 2011). Unfortunately, limited progress has been made due to more reliance on surface detection technologies which are challenged by response time. There is a widely accepted consensus in the industry to explore a bottom-up approach whereby kicks are detected early and can be tracked at multiple points along the wellbore. However, only limited progress has been made on this approach due to the complexity of offshore drilling operations. Velmurugan et al. (2015) presented an automated 
system for EKD and a control system that monitors and reports the physical conditions inside wellbore annulus instantaneously through time measurements of p-waves' propagation in the annulus. Its performance is questionable for field applications. Nayeem et al. (2016) experimentally investigated kick occurrence based on the changes in mass flow rate, pressure, density and conductivity of fluid downhole and concluded that the parameters have the potential to improve the kick detection system with higher precision than the surface detection system.

Vajargah and van Oort (2015) developed an algorithm that automatically selects a best well control response to influx in a drilling operation running a constant Bottomhole pressure (CBHP) managed pressure drilling (MPD); however, the paper did not clarify how this method will be implemented while running CBHP MPD operation in the field. Trivedi (2014) proposed an innovative kick detection system that uses a small mud rerouting section consisting of two plates and located just above the BHA. When there is an entrained formation fluid bubbles/droplet in the flow, the medium between the two plates will undergo alteration and form a magnetic impulse registering as abnormality in fluid flow, hence detecting kick. However, this technology has many limitations, including cuttings intrusion and capacitance limitations due to plate spacing. Ahmed et al. (2016) proposed a new advanced early kick detection method that uses seven parameters data (classified as instantaneous drilling parameters, e.g. pit gain, flow rate, ROP, etc., and lagging parameters, e.g. total gas connection gas, etc.) from mud logging while drilling; however, this method was field specific (Offshore Nile Delta field). Schubert and Wright (1998) proposed the use of an acoustic device installed on the casing valve to continuously monitor the liquid level in the annulus of wells experiencing complete loss of returns; thus, a rise in the liquid level is interpreted as early kick indication; however, this method has a limitation of lagging time that was not addressed by the authors.

DiFoggio and Duncan (2012) presented, in a patent, a tool and method that measure the acoustic velocity and temperature of a borehole fluid from an acoustic sensor and temperature sensor placed in a borehole to detect a gas influx in real time due to lower bulk modulus and density of the fluid and temperature drop. This is the closest and tested downhole detection methods but it is only limited to and/ or relied on borehole density and temperature parameters. Involving more downhole parameters in early kick detection indicators not only improve the reliability of kick detection but also provides the capability to validate kick occurrence when there are deviations in these parameters.

Thus, this paper experimentally monitors dynamic drilling parameters, including WOB, rotary speed, drilling vibrations during drilling that give an indication of gas kick. Many studies on kick detection rely on a flow-loop setup including flow valves, choke valve, and pressure sensors to simulate kick experiments. Therefore, the uniqueness of the current study lies in the utilization of a fully instrumented laboratory scale drilling rig to simulate drilling as the kick is being induced, controlled and monitored.

\section{Materials and methods}

\section{Experimental setup}

The setup consists of two integrated platforms: a fully instrumented laboratory scale drilling rig platform and a surface monitoring equipment and gas injection system platform. The drilling rig is equipped with a rotary head, fluid circulation system and a data acquisition system.

\section{Laboratory scale drilling rig}

The schematic diagram of the laboratory scale (scaleddown) drilling simulator is shown in Fig. 1a. The rig is powered by an electric drill motor with two rotational speed configurations ( 300 and $600 \mathrm{rpm}$ ) to provide adequate rotary speed and torque to the bit via the drillstring. The loading system consists of a rack-pinion arrangement through which a suspended weight, in addition to a constant weight, can be applied to the bit. The rotary head accounts for the constant weight on bit (WOB) and consists of the drill motor and the drillstring. The drillstring components include a cradle, a swivel, a compliant tool, and a drill pipe. The swivel allows the injection of fluid into the drill pipe down to the drill bit nozzles and the complaint tool, which is configured rigidly for the current experiment, provides a relative motion between the top system and the drill pipe using a set of coned-disc springs and rubber-damping elements. The drill pipe connects the drill bit with the top system (i.e. swivel, motor, etc.)

A 35-mm OD polycrystalline diamond cutter (PDC) bit with a two-cutter configuration is used as the drill bit in the current experiment. The mud circulation system is equipped with a 1000-L capacity water tank installed over a triplex pump powered by a $20-\mathrm{kW}$ motor with a flow rate and pressure capacities of $150 \mathrm{~L} / \mathrm{min}$ and $6900 \mathrm{kPa}$, respectively. The pump system also includes a variable frequency drive (VFD) to control the flow rate by adjusting the rotary speed of the motor. The circulation system includes a flow sensor, pressure transducer and water tank level meter to monitor and record the circulation conditions Khorshidan (2012). The water-based mud (WBM) is injected into the rig swivel assembly via a hose and then into an enclosed drilling/pressure cell.

The pressure cell, shown in Fig. 2, is located at the bottom of the rig system to serve as a wellbore and allow 


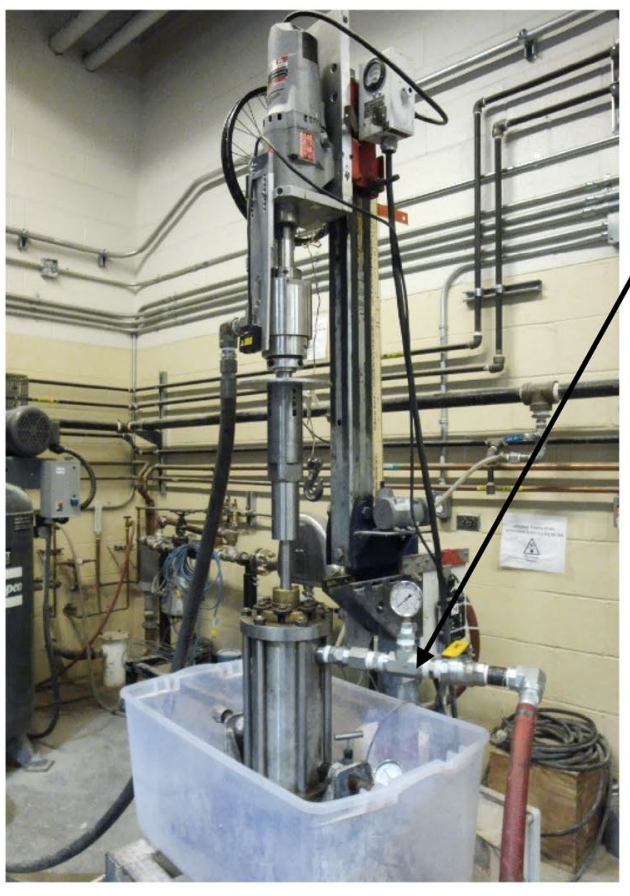

(a) Drilling rig simulator drainage line from

pressure cell to surface

monitoring equipment

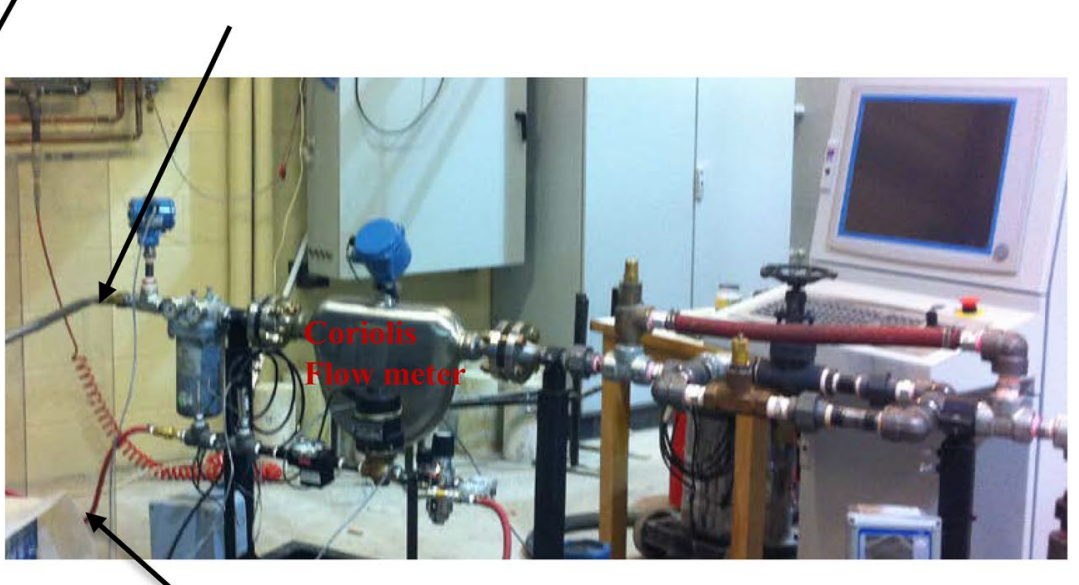

Gas injection line

(b) Surface monitoring and injection system

Fig. 1 Equipment setup for gas kick simulation experiment

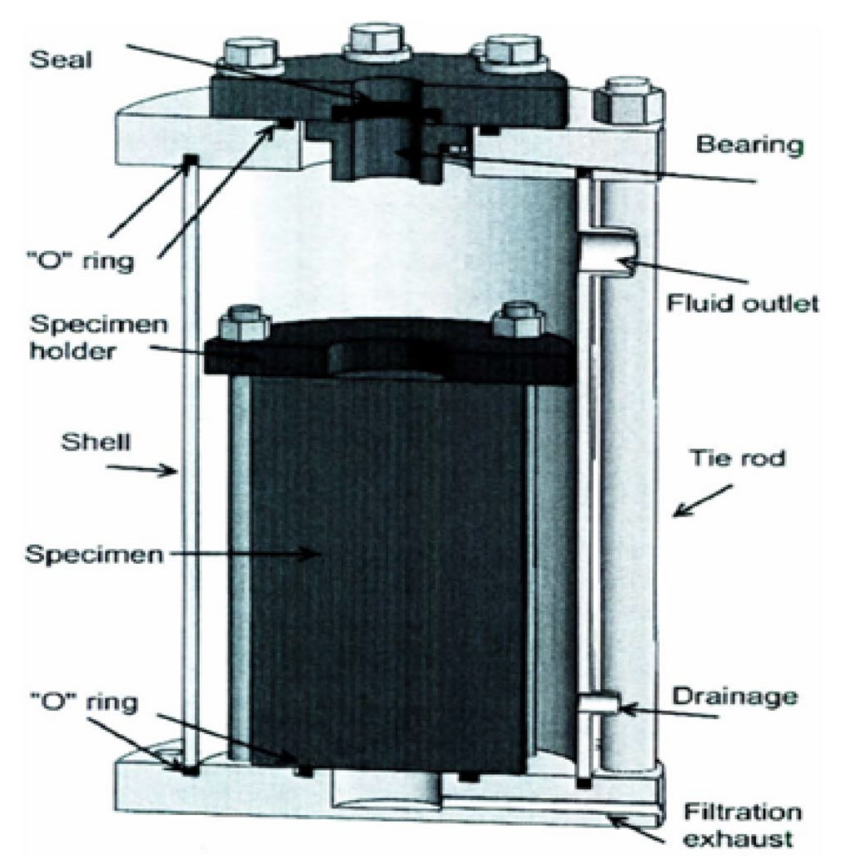

Fig. 2 Sectional view of a schematic drawing of a pressure cell (Source: Khorshidan 2012)

application of required bottomhole pressure during drilling. The pressure cell includes a clamping assembly to hold the rock specimen in place during drilling. In other words, the pressure cell serves as a closed wellbore through which confining pressure is applied to the rock specimen during drilling. The drillstring with attached PDC bit is inserted into the pressure cell through a top cap of the cell and rotary seals are placed within the cap to prevent leaks and keep the drillstring centered. The designed pressure of the cell is $2500 \mathrm{kPa}$ with a safety factor of 1.5 (Khorshidan 2012).

\section{Integrated surface monitoring equipment and kick injection system}

Surface monitoring equipment The surface equipment for monitoring surface parameters consists of a Coriolis flow meter, pressure transducer, $\mathrm{P}_{2}$, a flow in the choke manifold, and a conductivity sensor. A pressure transducer $\left(\mathrm{P}_{2}\right)$ located downstream of the pressure cell and upstream of the Coriolis flow meter, as shown in Fig. 1b, is used to measure the pressure in the return mud entering the surface monitoring equipment. The Coriolis flow meter is equipped with Elite flow sensor to provide good measurement sensitivity and stability when measuring multi-phase flow and it has tolerance for drill cuttings. The Coriolis flow meter is installed such that the tube is in the up orientation or flag up position to allow an effective drainage of cuttings and mud from the sensor. The choke manifold consists of three valves: a pressure relief valve installed on the pressure relief loop (line), a needle (or backpressure) valve to adjust backpressure in

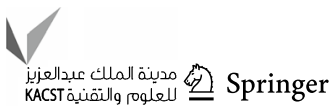


the downhole pressure in the pressure cell and a manual pressure control valve. In the event of a surge in the pressure cell, a pressure relief valve (PRV), installed upstream of the Coriolis flow meter, diverts flow to the pressure relief (bypass) line. The pressure control and needle valves are mainly used to control the downhole pressure. The conductivity sensor measures the electrolytic conductivity changes in the drilling mud return; however, was not monitored t due the sensor's incompatibility with drill cuttings.

Kick injection system The kick injection system is made up of an air compressor supply, a gas flow meter, a pressure sensor, a solenoid valve, and a check valve. The air compressor compresses air into an air pressure vessel and automatically shuts off at a pre-programmed pressure. The pressure vessel is equipped with a valve and a pressure gauge to discharge the pressured air and monitor the pressure in the vessel respectively during the experiment. The air pressure in the vessel is maintained between 120 and 150 psi.

A gas flow meter is used to measure, with accuracies of $\pm 5 \%$ in volume flow rate, the air pressure discharged into the pressure cell. The pressure sensor $\left(\mathrm{P}_{3}\right)$ on the air line measures the dynamic pressure injected into the downhole pressure cell. A solenoid valve, which is installed just downstream of the compressed air supply, is used to inject compressed air into the downhole pressure cell to simulate gas kick and the check valve installed close to the injection point to throttle any fluid attempting to flow in the reverse direction (Nayeem et al. 2016).

\section{Data acquisition system}

Two data acquisition (DAQ) systems are used to measure and acquire data for the experiments: a fixed DAQ system termed as DAQ \#1 and a portable DAQ system termed as DAQ \#2. The DAQ \#1 is interfaced with the drilling system to measure and acquire drilling-related parameters, including WOB, axial displacement, motor current. All data measured are recorded with a sampling rate of $1000 \mathrm{~Hz}$, which is the required minimum sampling rate to capture the axial displacement signals from the high precision laser sensor. The DAQ \#2 system measures and captures data from the integrated surface monitoring equipment and kick injection system, including downhole pressure in the pressure cell, gas pressure, mass and density flow. Because the DAQ \#2 has a $10-\mathrm{Hz}$ sampling rate capacity, the data from the two DAQ systems are compared using a clock synchronization technique.

\section{Rock specimens' preparation}

\section{Specimen properties}

The current experiment is performed on synthetic rock materials modelled by pouring a specified recipe of concrete slurry in $4 \times 4$-inch empty cylinders and left to set and harden. The concrete slurry mixture includes sand aggregates, water, cement, and superplasticizer. More information on concrete preparation can be found in Zhang (2017). The physical properties of the rock specimen used in the current study are shown in Table 1. The rock specimens are then stored in a controlled-moist environment to maintain their physical properties.

\section{Test specimen preparation}

The rock specimens are prepared so that gas injected from the base of the rock can interact with the rotating bit as it cuts through the rock. To accomplish this objective, a hole is drilled through the center of the rock. As shown in Fig. 3a-d, the test specimen preparation is completed through the following steps:

a. Step 0 Showing the test specimen in its original state, Fig. 3a

b. Step 1 The center of the rock is laid out and located as shown in Fig. 3 b.

c. Step 2 A $1 / 4$ inch Masonry bit is used in a drill press to drill a hole through the rock center of the rock as shown in Fig. 3c.

d. Step 3 The top and bottom surfaces of the rocks are sanded to smoothly fit into the pressure cell base that will house the specimens during drilling shown in Fig. 3d.

\section{Bit operation analysis}

The bit operation analysis is conducted to ensure that the input parameters set for the experiment are within the operational requirements of the drilling rig simulator. For this

Table 1 Physical properties of the synthetic rock specimen (source: Zhang 2017)

\begin{tabular}{lll}
\hline Rock property & Value & Units \\
\hline $\begin{array}{l}\text { Unconfined compressive strength } \\
\text { (Ucs) }\end{array}$ & 51 & Mpa \\
Mohr friction angle & 40 & \\
Tensile strength & 5.4 & Mpa \\
Young modulus & 29 & Gpa \\
Poisson ratio & 0.15 & \\
\hline
\end{tabular}


Fig. 3 Test specimen preparation: steps $0-3$

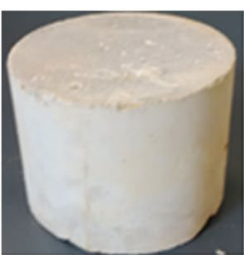

(a)

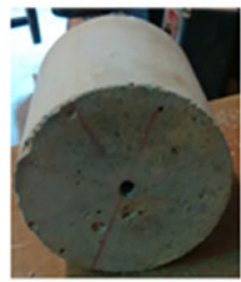

(c)

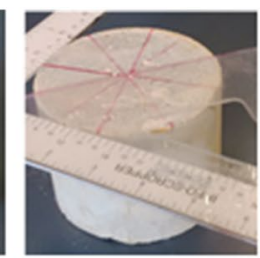

(b)

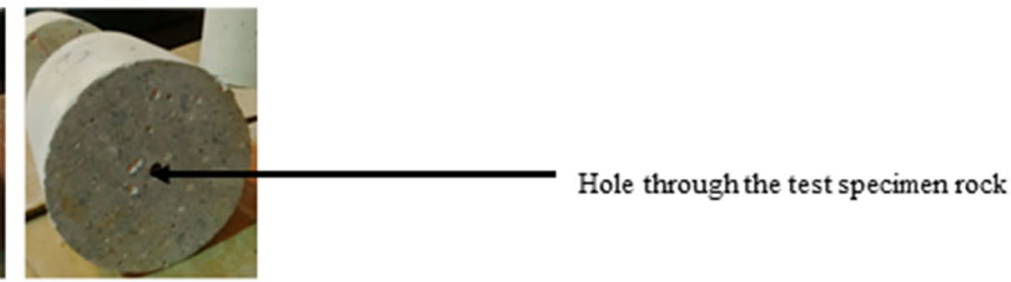

(d) experiment, a PDC bit with an outer diameter of $35 \mathrm{~mm}$ and two nozzle configurations with a diameter of 5.7/32-in (or 0.178125-in) each is used. The dynamic weight on bit (WOB) is measured directly from the load cell. The WOB measured by DAQ \#1 during the experiment is not an effective WOB due to pump-off pressure and force underneath the bit. Hence, the effective WOB can be determined by the following equation:

$\mathrm{WOB}_{\text {eff }}=\left(\mathrm{WOB}_{\text {measure }}\right)-($ pump-off force $)$.

Hydraulic pump-off force (HPO) can either be measured during a drill-off test or estimated by the following equation:

$\mathrm{HPO}=4.1902 \Delta P_{\mathrm{bit}}\left(d_{\mathrm{bit}}-1\right) \quad[\mathrm{N}]$,

where $\Delta P_{\text {bit }}[\mathrm{Pa}]$ is the pressure drop across the bit and $d_{\mathrm{bit}}$ $[\mathrm{m}]$ is the nozzle diameter in the bit.

The pressure drop across the bit can be calculated using the following equation:

$\Delta P_{\mathrm{bit}}=\frac{9.523 \times 10^{-5} \rho q^{2}}{C_{\mathrm{d}}^{2} A_{\mathrm{t}}^{2}} \quad[\mathrm{~Pa}]$

where $\rho$ is the density $\left(\mathrm{kgm}^{3}\right) ; q$ is the pump flowrate $\left(\mathrm{m}^{3} / \mathrm{s}\right)$; $C_{\mathrm{d}}$ is the jet nozzle discharge coefficient $=0.95$; and $A_{\mathrm{t}}$ is the total nozzle area $\left(\mathrm{m}^{2}\right)$. The hydraulic pump-off force obtained using the above equations is $\mathbf{- 1 6 6 . 8 N}$. The negative sign shows that HPO is a negative weight on bit. Therefore, the effective weight on bit, $\boldsymbol{W O B}_{\text {eff }}$, can be calculated using Eq. (1). Additionally, nozzle jet force $F_{\mathrm{j}}$, which is the impact force developed by the bit, can be calculated using the following equation:

$F_{\mathrm{j}}=1.0588 \times 10^{-3} C_{\mathrm{d}} q\left(\sqrt{\rho \Delta P_{\mathrm{bit}}}\right) \quad[\mathrm{N}]$.

Thus, the nozzle jet force calculated, $F_{\mathrm{j}}=\mathbf{1 9 . 3 5} \mathrm{N}$. Another important parameter to be considered is the hydraulic square inch (HSI) which is a function of pump hydraulic
Table 2 Summary of input simulation parameters

\begin{tabular}{llll}
\hline Parameters & Description & Values & Units \\
\hline WOB & Applied weight on bit & 54.3 & $\mathrm{~kg}$ \\
$q$ & Mud pump input flow rate & 47.3 & $\mathrm{~L} / \mathrm{min}$ \\
$P_{\mathrm{i}}$ & Initial downhole pressure & $30-35$ & $\mathrm{psi}$ \\
$P_{\mathrm{g}}$ & Compressed gas input pressure & $170-180$ & $\mathrm{psi}$ \\
$Q$ & Compressed air input flow rate & $8-9$ & $\mathrm{SCFM}$ \\
$N$ & Drilling motor speed & $292-300$ & $\mathrm{Rpm}$ \\
$\rho_{\text {mud }}$ & Water base mud density & 1000 & $\mathrm{~kg} / \mathrm{m}^{3}$ \\
\hline
\end{tabular}

horsepower $\left(P_{\mathrm{hp}}\right)$ and bit area and can be determined using the following equations, respectively,

$P_{\mathrm{hp}}=\frac{\Delta P_{\mathrm{bit}} q}{1714}(\mathrm{hp})$

$\mathrm{HSI}=\frac{P_{\mathrm{hp}}}{A_{\mathrm{bit}}}\left(\mathrm{hp} / \mathrm{in}^{2}\right)$,

$P_{\mathrm{hp}}=0.353 \mathrm{hp}$ and $\mathrm{HSI}=0.238 \mathrm{hp} / \mathrm{in}^{2}\left(\right.$ or $\left.2.75 \mathrm{~kW} / \mathrm{m}^{2}\right)$ are obtained. Therefore, the bit size and the hydraulic horsepower requirement for this experiment are well within the specifications for the drilling simulator and Table 2 provides the summary of the input parameters used in the experiment.

\section{Experimental procedure}

The drilling of the test specimens is planned and conducted such that the depth of specimen drilled experiences three consecutive stages of drilling simulation: no-kick region 1 (NKR-1), kick region (KR), and no-kick region 2 (NKR2) respectively. Approximately $80 \%$ of the test specimen with 4-in total depth is drilled for each run to ensure the test specimen fully interacts with the two PDC cutters and 


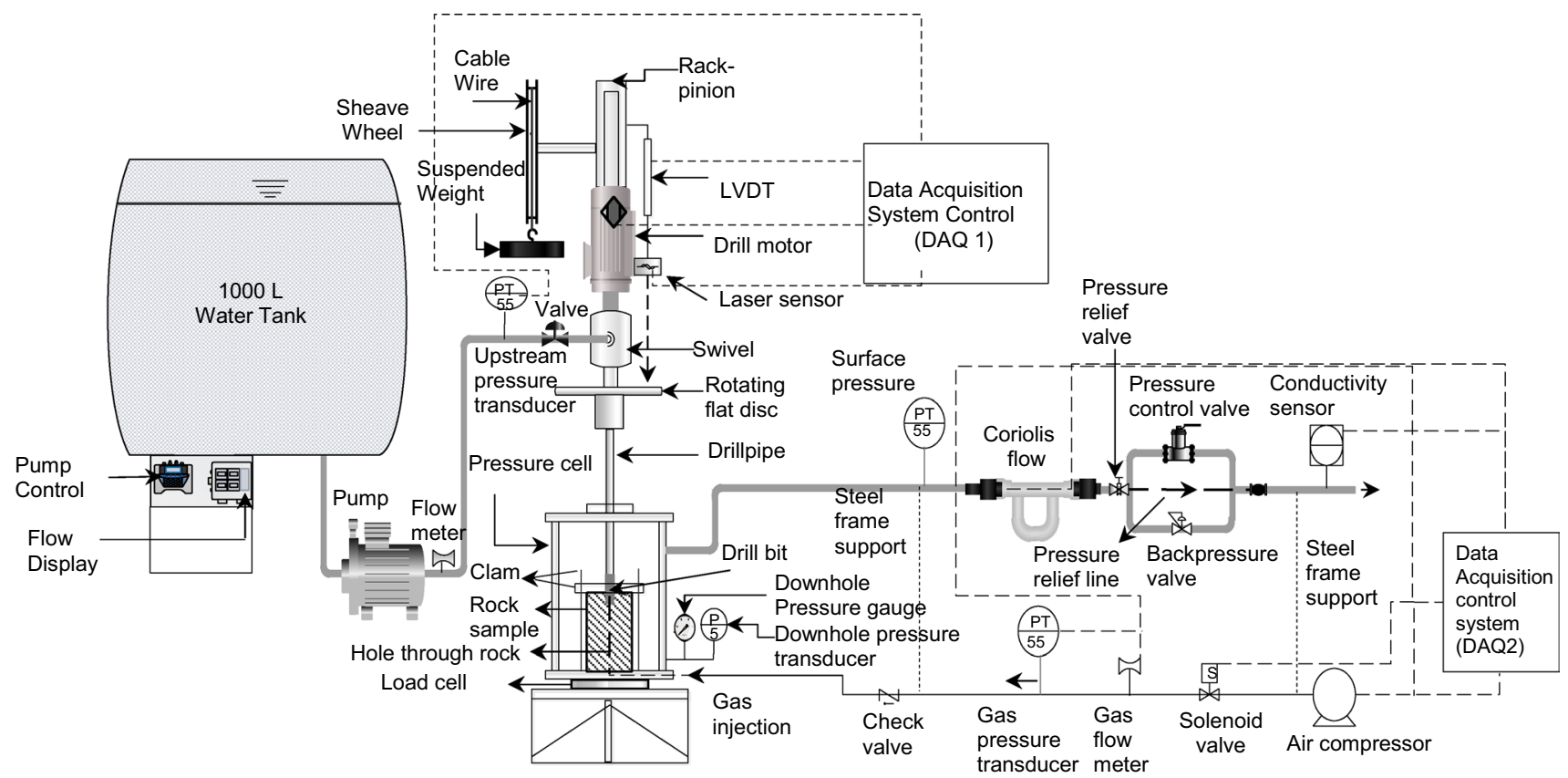

Fig. 4 Kick experiment process flow diagram

remains intact after drilling simulation. The air is injected into the test specimen via the filtration exhaust of the downhole pressure cell, as shown in Fig. 4. The test procedure is conducted as follows:

a) The drilling procedure begins by installing the test specimen in the downhole pressure cell, which becomes a closed wellbore.

b) The experiment commences after the test specimen secured in the pressure cell and simulation equipment has been fully set up as shown in Fig. 4 .

c) After drilling about one-third of the test specimen depth (NKR-1), compressed air is injected into the pressure cell at a fixed rate of 8-9 SCFM and the pressured air travels from the bottom of the test specimen to the top via the hole through the centre of the specimen. This enables the bit-rock-air interactions and simulates the kick region (KR).

d) After drilling approximately another one-third or more of the test specimen during kick, the air injection is stopped as the drilling continues with no kick (NKR-2). During this operation, downhole parametric data, including rotary angular speed, rate of penetration (ROP), average depth of cut, axial displacement of the bits, motor current and WOB are logged by DAQ $\# 1$, while the downhole pressure, inlet pressure into the return line, return mud mass flow and density flow rates are logged by DAQ \#2.

\section{Results and discussion}

Six downhole dynamic drilling parameters that are measured and calculated during experimental simulations are weight on bit (WOB), torque on bit (TOB), downhole pressure, rate of penetration (ROP), rotary speed and bit axial displacement (vibrations). In addition to these parameters, four surface parameters are monitored and these include choke pressure, return fluid mass flow rates, volume flow rates, and density. Two experimental runs are conducted to ensure repeatable and consistent results. The results from these experiments have been compared and found consistent with Aldred et al. (1998) field reports on drilling parameters' response to kick.

Aldred et al. (1998) reports focused on the performance of annular pressure while drilling tools, along with other BHA tools, for monitoring drilling performance and making proactive decisions during drilling operations. These tools were utilized in the Eugene Island field in the Gulf of Mexico where the formation consisted of sequences of shales and target sands that were likely depleted by previous production. The drilling contractor, anadrill, utilized series of downhole tools, including the compensated dual resistivity, multi-axis vibrational cartridge, integrated weight on bit, and annular pressure while drilling for this well. Thus, drilling parameters including downhole torque and weight on bit, axial and torsional vibrations, ROP, annulus pressure, equivalent circulating density (ECD) were being measured. When kick was taken in a $12 \frac{1}{4}$-in hole section, their measurements started to drop 


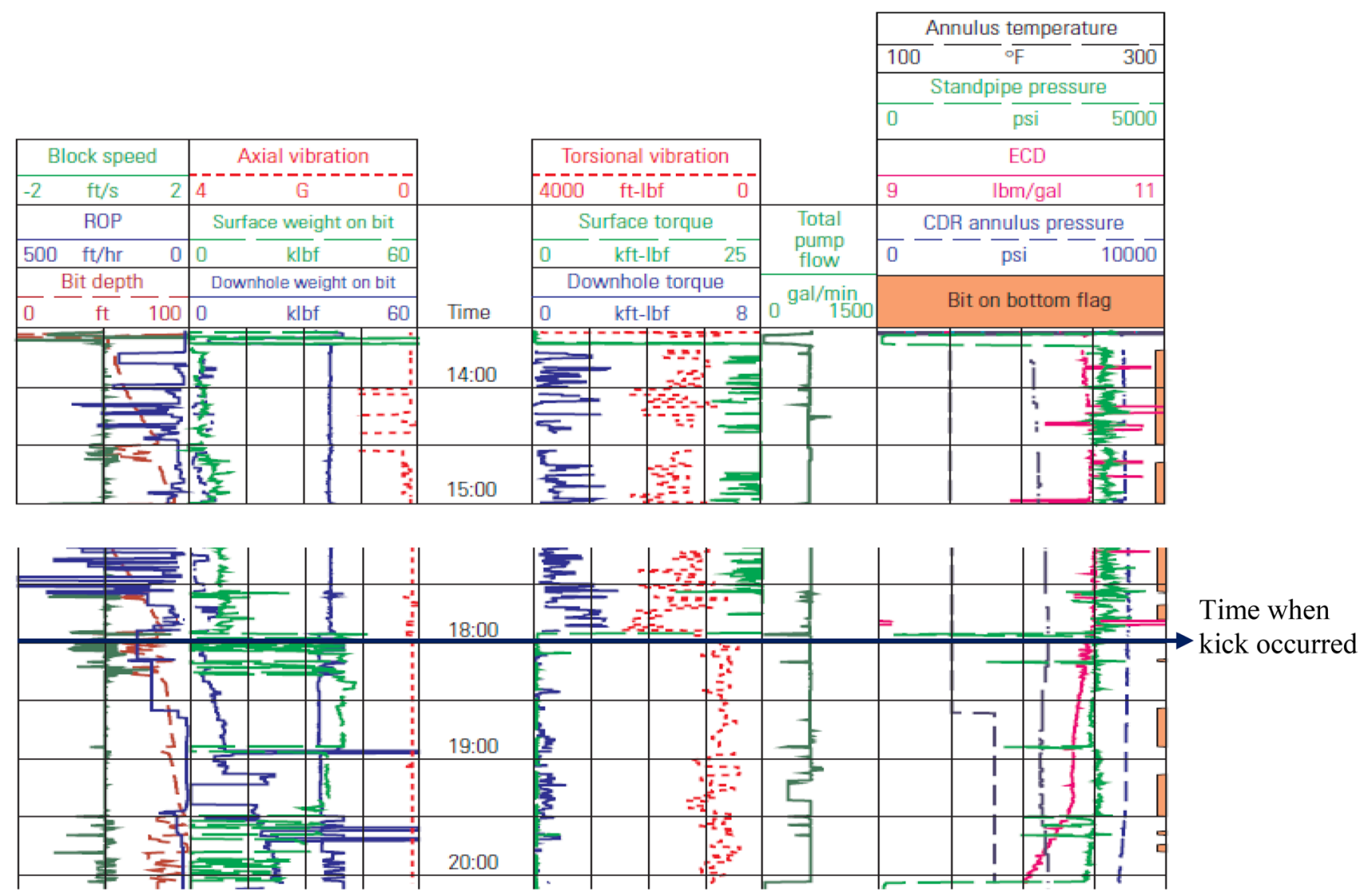

Fig. 5 Reproduced well log with respect to time showing the kick alert in the GOM well (Source: Aldred et al. 1998)

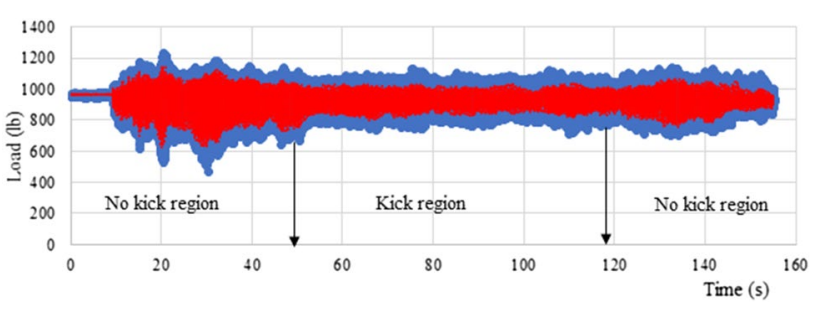

Fig. 6 Effects of gas kick on WOB for experimental Run_1

in response to kick. These deviations can be observed in Fig. 5, i.e. ROP, WOB, annulus pressure, torques, vibrations, and ECD dropped due to kick. These responses in drilling parameters indicating kick occurrence are found to have consistent responses with the experimental results that are being presented in this section.

\section{Kick effects on downhole WOB and pressures}

The effects of kick on drilling parameters, such as WOB and bottomhole pressures for both experimental runs are shown in Figs. 6, 7, 8 and 9. Figures 6 and 7 show the effects of

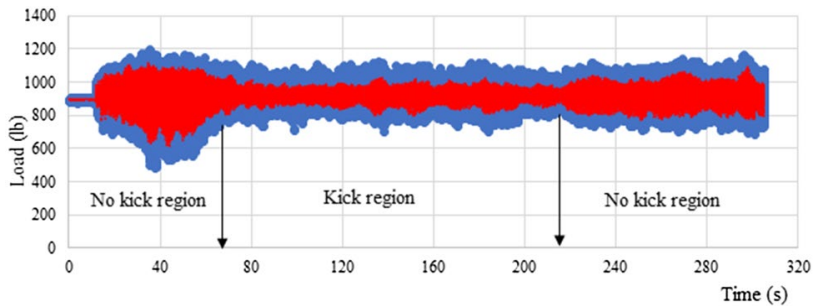

Fig. 7 Effects of gas kick on WOB for experimental Run_2

kicks on WOB for both Run_1 and Run_2, respectively. It is observed from both curves that the WOB decreases in magnitude after the kick is initiated. The moment when the kick is injected into the drilling system is consistent with the moment when the downhole and output pressures surge by an average of 25-45 psi above the initial downhole pressure, as shown in Figs. 8 and 9 of Run_1 and Run_2, respectively.

\section{Kick effects on ROP}

The kick effects on the rate of penetration (ROP) can be observed in Figs. 10 and 11 of Run_1 and Run_2, 


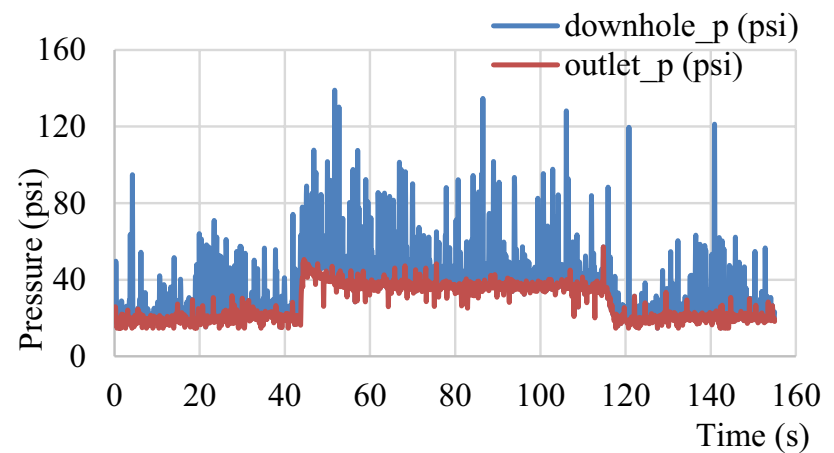

Fig. 8 Effects of gas kick on bottomhole pressure for experimental Run_1

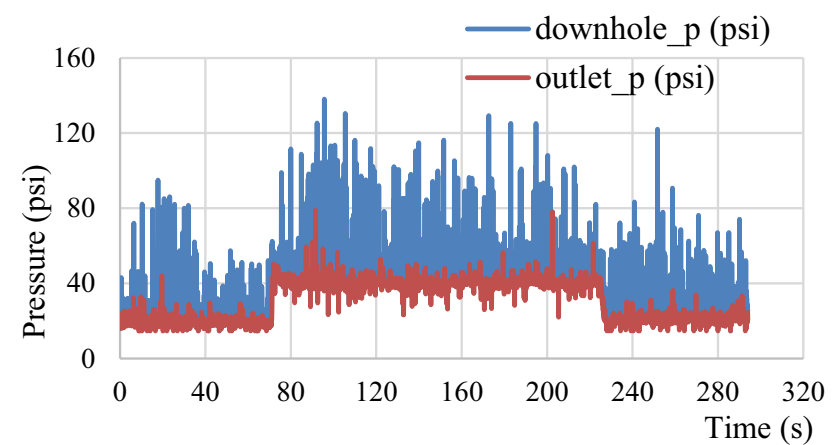

Fig. 9 Effects of gas kick on bottomhole pressure for experimental Run_2

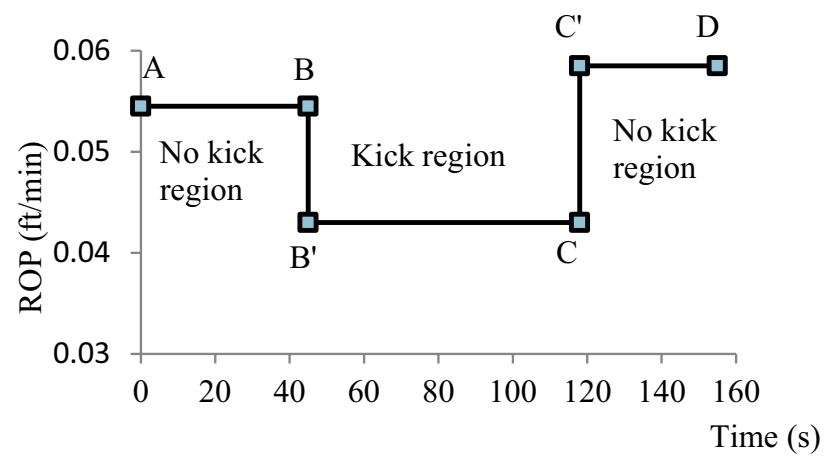

Fig. 10 Effects of gas kick on ROP for experimental Run_1

respectively. As shown from point A to point B of the nokick region 1 , the ROP value is $0.055 \mathrm{in} / \mathrm{s}(1.4 \mathrm{~mm} / \mathrm{s})$. As soon as kick occurs (i.e. gas injection into the wellbore) the ROP drops to about $0.04 \mathrm{in} / \mathrm{s}(1.02 \mathrm{~mm} / \mathrm{s})$ from point B to B', which represents about a $27 \%$ drop. From point $\mathrm{B}^{\prime}$ to point $\mathrm{C}$, the ROP remains constant in this kick region. When the air injection ceases at point $\mathrm{C}$, the ROP increases to about $0.058 \mathrm{in} / \mathrm{s}(1.5 \mathrm{~mm} / \mathrm{s})$ for Run_1 and $0.055 \mathrm{in} / \mathrm{s}(1.4 \mathrm{~mm} / \mathrm{s})$ for Run_2 from point $\mathrm{C}$ to $\mathrm{C}^{\prime}$. This may be explained by

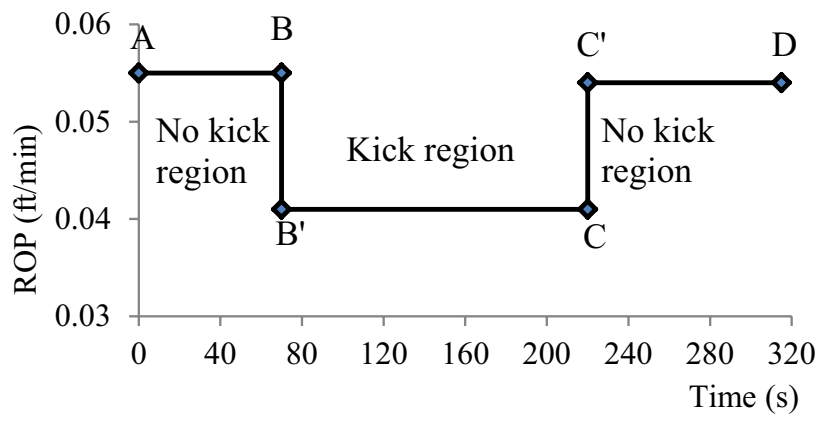

Fig. 11 Effects of gas kick on ROP for experimental Run_2

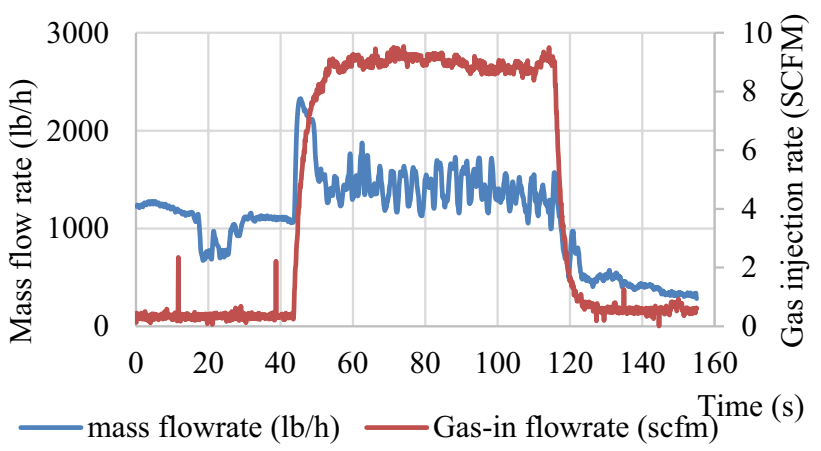

Fig. 12 Effects of gas kick on mass flow rate of the return fluid for experimental Run_1

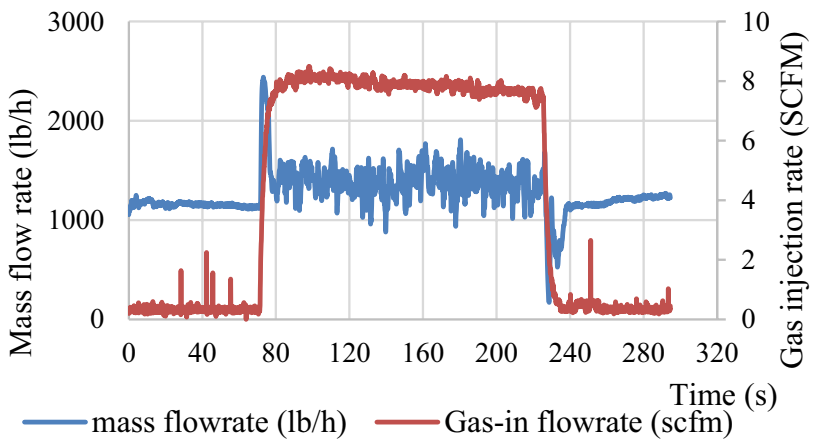

Fig. 13 Effects of gas kick on mass flow rate of the return fluid for experimental Run_2

the upthrust force, which creates an air jet between the bit and the core rock specimen, thus lifting the bit and causing minimal bit-rock interactions.

\section{Kick effects on mud return volume flow rate}

The effects of kick on the mass flow rate of the mud return for Run_1 and Run_2 are shown in Figs. 12 and 13, respectively. The mass flow rate responds instantaneously to gas influx entering the flow meter as shown by a surge in the 


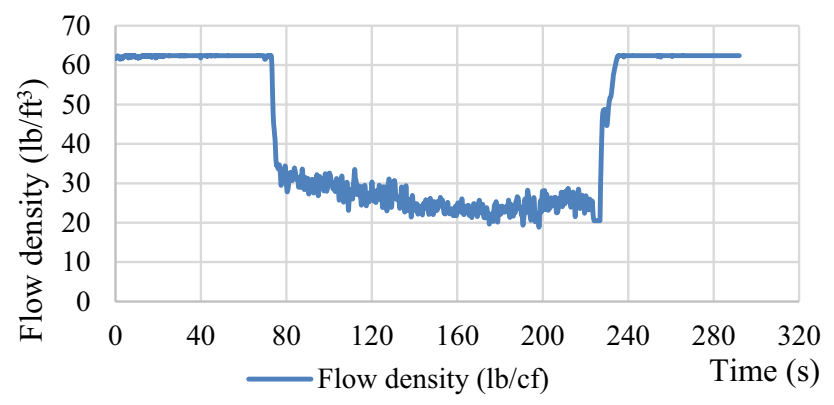

Fig. 14 Effects of gas kick on mud density of the return fluid for experimental Run_2

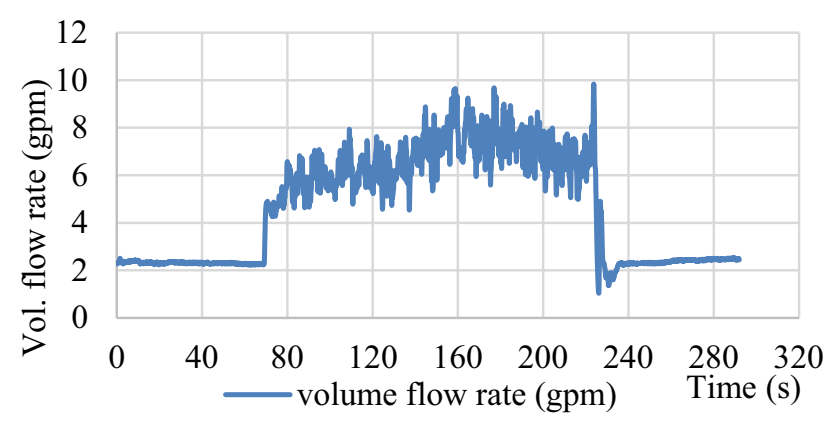

Fig. 15 Effects of gas kick on volume flow rate of the return fluid for experimental Run_2

mass flow rate of the return mud. The continuous injection of compressed air (influx) into the wellbore then causes erratic readings of the mass flow rate that, by observation, is on average higher in magnitude than the pre- and post-gas kick readings. The observed increase in the mass flow rate may be due to the increased mass velocity of the fluid caused by gas influx.

Additionally, the effects of kick on fluid density are shown in Fig. 14. The fluid density is observed to drop in magnitude due to the gas influx. This can be explained by the low-density fluid (air) injected into the wellbore mud decreasing the bulk density of the return mud. Since the volume flow rate is determined by dividing the mass rate by the combined fluid density, the volume flow rate increases due to gas kick; this effect is shown in Fig. 15.

\section{Kick effects on rotary speed}

The minimal bit-rock interactions created by the upthrust jet during air injection into the wellbore for Run_1 and Run $\_2$ may also explain the reason for the increase in rotary speed. The rotary speed is calculated from the relative displacement data acquired from the laser sensor projection on a rotating disc by means of counting the number of spikes created by the three grooves located on

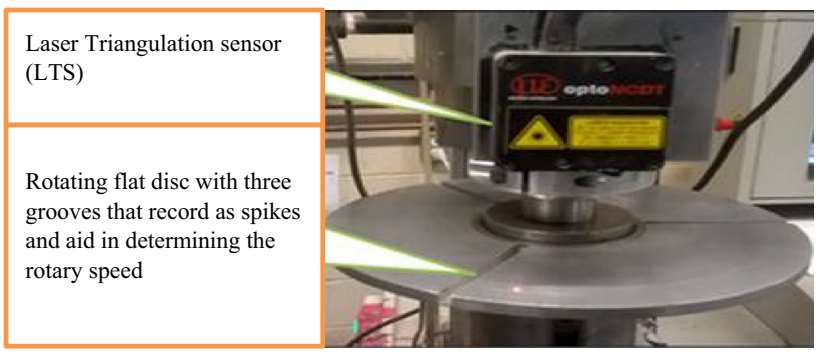

Fig. 16 An image of a rotating flat disc with three grooves for measuring relative displacement between the motor head and the drill pipe

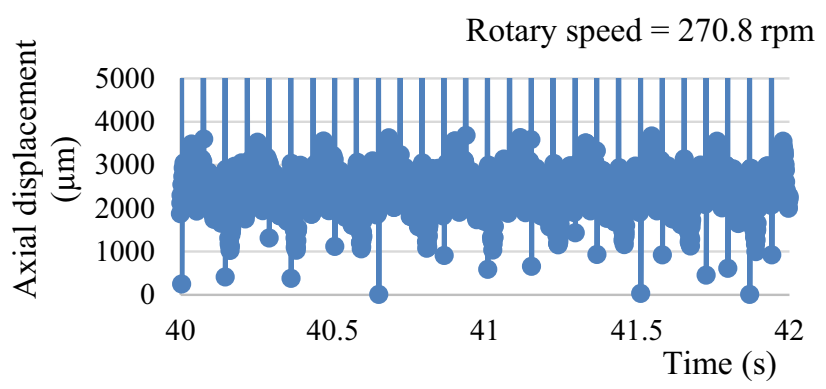

Fig. 17 Kick effects on rotary speed—no-kick region \#1 for Run_1

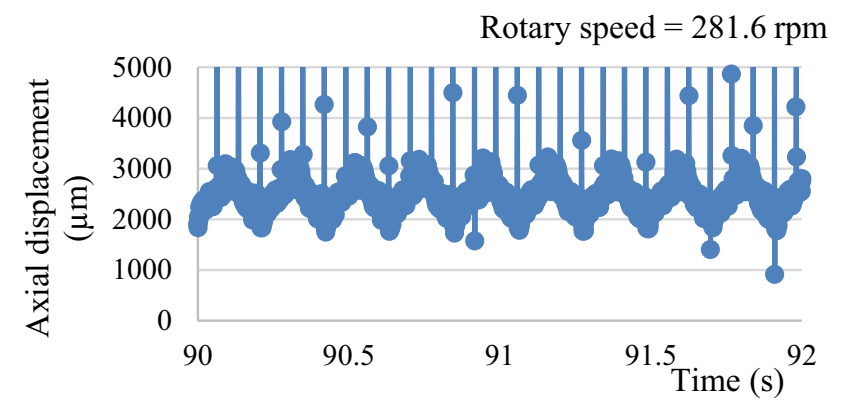

Fig. 18 Kick effects on rotary speed—kick region for Run_1

the plate $120^{\circ}$ apart, as shown in Fig. 16. These grooves are recorded as spikes in the bit-rock axial displacement data as the tool rotates during drilling. These spikes can be noted in Figs. 17, 18 and 19 for Run_1 and Figs. 20, 21 and 22 for Run_2 of the axial bit displacements versus time graphs. The rotary speed for each test condition, is thus calculated by the following procedures a) to c) and the results are summarized in Table 3:

a) The rotary speed (RPM) calculation can be determined by counting the number of spikes between the 2-s period and then calculate the average of spikes per 1-min revolution. 


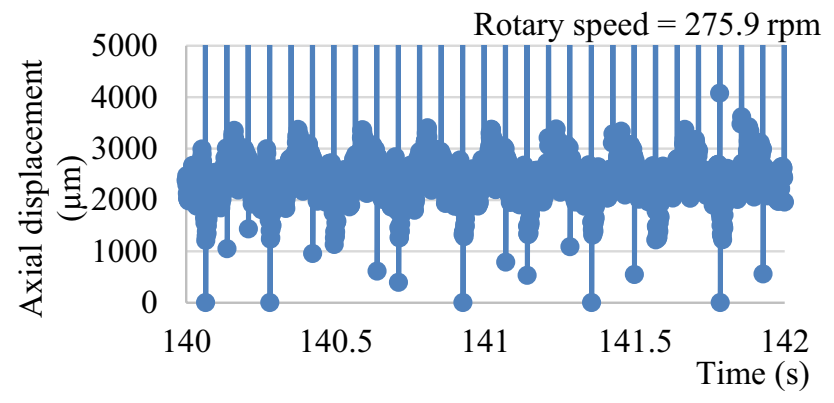

Fig. 19 Kick effects on rotary speed—no-kick region \#1 for Run_1

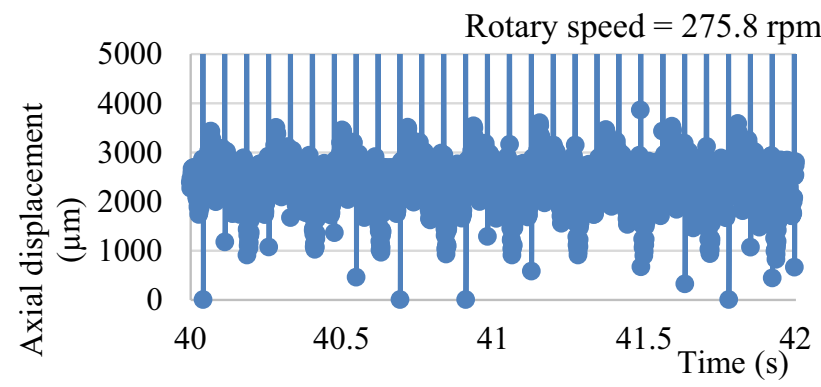

Fig. 20 Kick effects on rotary speed—no-kick region \#1 for Run_2

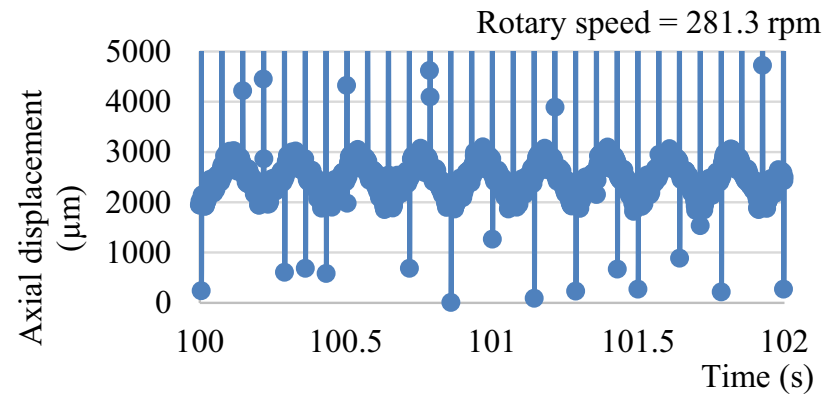

Fig. 21 Kick effects on rotary speed—kick region for Run_2

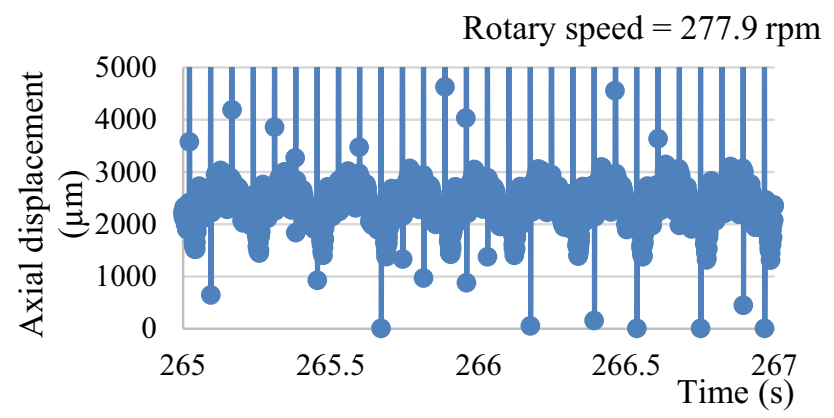

Fig. 22 Kick effects on rotary speed-no-kick region \#2 for Run_2
Table 3 Summary of calculated rotary speeds during kicks and nokick drilling simulations

\begin{tabular}{lll}
\hline Test specimen phase & $\theta(\mathrm{Rpm})$ for Run_1 & $\begin{array}{l}\theta(\mathrm{Rpm}) \\
\text { for } \\
\text { Run_2 }\end{array}$ \\
\hline No-kick zone 1 & 270.8 & 275.8 \\
Kick zone & 281.6 & 281.3 \\
No-kick zone 2 & 275.9 & 277.9 \\
\hline
\end{tabular}

b) Equation (7) is developed to calculate the rotary speed of the drillstring as it experiences drilling phase/region.

c) The rotary speed for each test condition is thus calculated and the results are summarized in Table 3.

$\theta(\mathrm{RPM})=\frac{(\# \text { of spikes }) \times 3}{60} \times(\Delta T)$,

where $\theta$ is the rotary speed and $\Delta T$ is the time between the first spike and the last spike.

Figures 17, 18, 19, 20, 21 and 22 represent 2-s data from each testing region of the test specimen core rock for Run_1 and Run_2. Figures 17, 18, and 19 show the bit axial displacement data for NKR-1, KR, and NKR_2, respectively for Run_1 while Figs. 20, 21, and 22 show the same for Run_2. It can also be observed that the intensity of the noise in the bit-rock displacement data completely dampens out as the test specimen undergoes drilling with no-kick and when kick is injected. These dampening effects show the indication of kick, which is evident by a dramatic reduction in axial bit-rock displacements during the kick.

\section{Kick effects on torque on bit (TOB)}

The effects of kick on TOB are also explored, as TOB can be a significant downhole parameter candidate for early kick indicator. Although no direct measurement of TOB is currently installed on the drilling system, Reyes (2017) performed a series of laboratory tests using the drilling system utilized in the current study and a MC6 Load and torque cell equipment to develop a mathematical relationship between TOB, drill motor current and rotary speed. The motor current and rotary speed are measured using the DAQ \#1. The detail procedures are available in Reyes (2017). This formula is given in the following equation:

$\operatorname{TOB}\left(\Omega, i_{\text {rms }}\right)=59.985-0.295 \Omega+26.48 i_{\text {rms }}(\mathrm{Nm})$,

where $\Omega=$ the angular speed (RPM) and $i_{\text {rms }}=$ root mean square of motor current.

By applying (8), the average TOB at each test region [nokick (1), kick, and no-kick (2)] for experimental Run_1 and Run_2 are determined and summarized in Fig. 23. It can be 


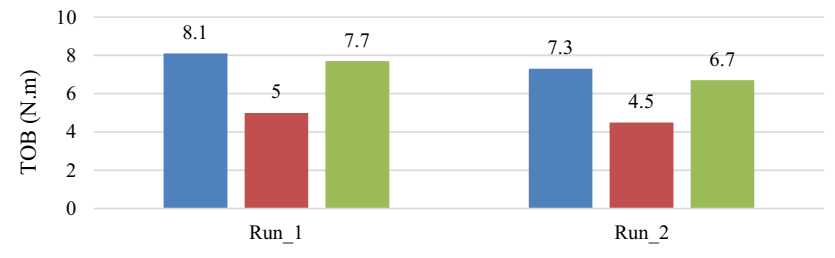

- 1 No-kick region \#1 (NKR-1) $\backsim 2$ Kick region (KR) $₫ 3$ No-kick region \#2 (NKR-2)

Fig. 23 Kick effects on TOB for experimental Run_1 and Run_2

observed that the average TOB drops when kick is experienced in the wellbore (pressure cell). This may be consequential to the lift force exerted by the air jet underneath the bit reducing the interactions between the bit and the core specimen. This reduction in interactions will lower the driving force (or TOB) required to drill the core specimen compared to the higher driving force required when the wellbore is not experiencing kick, which will thus increase the TOB.

These results are consistent with behaviour of all other drilling/downhole parameters that are explored in this work. For example, the kick region experiences a higher rotary speed, lower TOB and lower ROP compared to a lower rotary speed, higher TOB, and higher ROP for a no-kick region. These results are also consistent with the field data reported in Aldred et al. (1998). It can be concluded that a dramatic drop in TOB during drilling can be an indication of kick occurrence downhole.

\section{Bit-rock interaction and analysis}

The most significant new finding of this work is the dampening effect of drilling vibrations due to kick. These are captured in Figs. 17, 18 and 19 of Run_1 and 20-22 of Run_2. By using a time-scale analysis, 2-s (precisely $2.048 \mathrm{~s}$ ) data are extracting from Run_1 plots in Fig. 16, 17, and 18 and plotted them to place the data response of each test region sequentially for visualization. The result, as illustrated in Fig. 24, shows significant changes in the axial displacement and vibration as the core specimen experiences the no-kick region (1) $\rightarrow$ kick region $\rightarrow$ no-kick region (2) sequence.

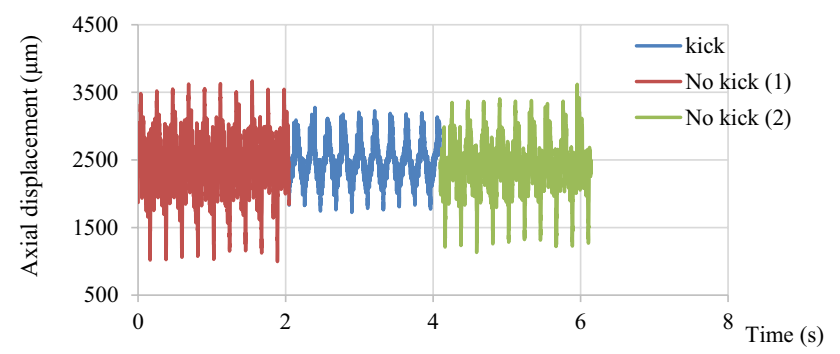

Fig. 24 Kick effects on axial bit-rock displacement (time domain)Run_1
This behaviour may constitute an indication of influx into the wellbore.

Additionally, a frequency analysis is performed using fast Fourier transform (FFT) as a data processing method, which converts the data from time-scale domain into frequency domain. The purpose for performing frequency analysis is to identify different frequencies in the data. By default, the overall bit axial displacement also consists of axial vibration, which is of interest to this analysis. The current work adopts Reyes (2017) methodology to perform the data processing for the overall bit axial vibration frequency analysis using the following equation:

$U_{\text {vib }}=\left(T \times \mathrm{ROP}_{\mathrm{Avg}}\right)-U$,

where $U_{\text {vib }}$ is the axial vibration; $T$ is the time; $\mathrm{ROP}_{\text {avg }}$ is the Average ROP; $U$ is the axial displacement.

By applying this methodology and process, the axial displacement frequencies obtained are signals as shown in Fig. 25. It can be noted that there is a significant drop in the bit axial vibration during kick as compared to no-kick conditions.

\section{Conclusions}

The current study monitored nine parameters, including dynamic WOB, downhole pressure, ROP, rotary speed, TOB, axial bit-rock interaction vibration, mud density, return mass flow rate, and return volume flow rate. These parameters are measured during lab-scale drilling simulations of synthetic core specimens with a hole drilled through the center to aid bit-rock-gas influx interactions. Each core specimen undergoes three consecutive test stages during drilling: no-kick region (1), kick region (KR), and no-kick region (2). The results from all monitored parameters show that influx indications are consistent with case studies and field reports and are summarized as follows:

a) $W O B$ The magnitude of WOB decreases in response to gas influx.

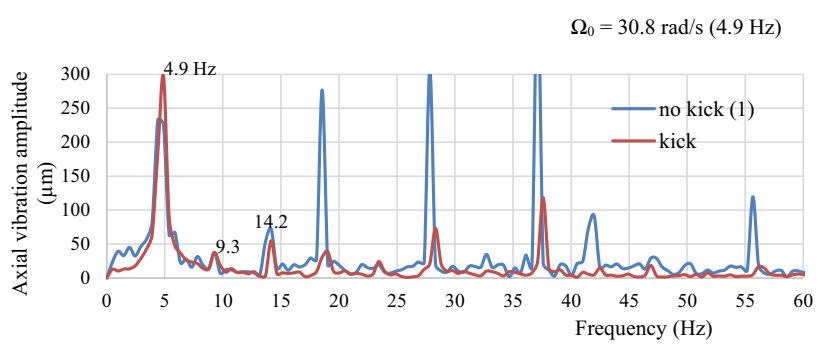

Fig. 25 Kick effects on axial bit-rock vibration frequency-Run_1

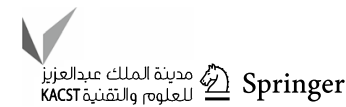


b) Downhole pressure There is an immediate surge in downhole pressure in response to kick.

c) Mud return flow rate Mud density drops in response to kick and the volume flow rate increases in response to kick.

d) $R O P$ The rate of penetration drops during gas influx and this may be explained by less bit-rock interaction due to the air jet exerted below the bit.

e) Rotary speed and TOB The rotary speed increases when kick is experienced in the wellbore while the TOB decreases. These behaviours may be explained due to less bit-rock interactions causing the drillstring to rotate faster and with less driving force.

f) Axial bit vibration The amplitude of axial bit vibration significantly decreases as the kick is taking in the wellbore.

The most significant new finding of the study is the dampening behaviour of drilling vibrations due to gas influx. This is evidenced by a dramatic reduction in axial bit-rock displacement/vibration during the kick and the behaviour are illustrated in both time and frequency scales analyses. The dampening effects of drilling vibrations during kick can potentially serve as a new influx indicator during drilling with more large-scale/field investigations. Thus, for most drilling scenarios where temperature and pressure are higher, the kick size, rate, and rising time are expected to be higher; however, these conditions will not change how the drilling parameters will respond to the kick occurrence and detection given that appropriate downhole and surfacesensing devices are used. Therefore, the drilling parameters measured and studied in the current paper are expected to respond consistently to gas kick in all practices as indicated and concluded.

Acknowledgements The authors acknowledge the financial support from the Natural Sciences and Engineering Research Council (NSERC) of Canada, Vale Research Chair Grant, National Research Council Canada (NRC), and Research and Development Corporation of Newfoundland and Labrador (RDC).

Open Access This article is distributed under the terms of the Creative Commons Attribution 4.0 International License (http://creativeco mmons.org/licenses/by/4.0/), which permits unrestricted use, distribution, and reproduction in any medium, provided you give appropriate credit to the original author(s) and the source, provide a link to the Creative Commons license, and indicate if changes were made.

\section{References}

Ahmed MA, Hegab OA, Sabry A (2016) Early detection enhancement of the kick and near-balance drilling using mud logging warning sign. Egypt J Basic Appl Sci 3(1):85-93. https://doi.org/10.1016/j. ejbas.2015.09.006

Aldred W, Cook J, Bern P, Carpenter B, Hutchinson M, Lovell J, Rezmer-Cooper I, Leder PC (1998) Using downhole annular pressure measurements to improve drilling performance. Oilfield review. http://www.slb.com/ /media/Files/resources/oilfield_revie w/ors98/win98/using.pdf. Accessed 12 Nov 2016

DiFoggio R, Blue DD (2012) Early kick detection in an oil and gas well. US Patent 2012/0170406 A1, published July 5. http://www. google.com/patents/US20120170406. Accessed 16 Nov 2016

Graham B, Reilly WK, Beinecke F, Boesch DF, Garcia TD, Murray CA, Ulmer F (2011) Deep water, the Gulf oil disaster and the future of offshore drilling. National commission on the BP deepwater horizon oil spill and offshore drilling. https://www.gpo.gov/ fdsys/pkg/GPO-OILCOMMISSION/pdf/GPO-OILCOMMISS ION.pdf. Accessed 21 Dec 2016

Khorshidan H (2012) Phenomena affecting penetration mechanisms of polycrystalline diamond compact bits. Master thesis, Faculty of Engineering and Applied Science, Memorial University of Newfoundland, St. John's, NL. http://research.library.mun.ca/id/eprin t/2357. Accessed 25 Aug 2016

Nayeem AA, Ramachandran V, Khan F (2016) Monitoring of downhole parameters for early kick detection. J Loss Prev Process Ind 40:43-54. https://doi.org/10.1016/j.jlp.2015.11.025

Reyes NR (2017) Bit-rock interaction in rotary drilling: numerical and experimental study. Master thesis, Faculty of Engineering and Applied Science, Memorial University of Newfoundland, St. John's, NL

Schubert JJ, Wright JC (1998) early kick detection through liquid level monitoring in the wellbore. Presented at IADC/SPE drilling conference held in Dallas, Texas. 3-6 March. https://doi. org/10.2118/39400-MS

Trivedi PP (2014) Innovative kick detection system for HP/HT ultradeepwater wells using a section of the BHA. Paper presented at the Offshore technology conference held in Houston, Texas, USA. 5-8 May. https://doi.org/10.4043/25074-MS

Vajargah AK, van Oort E (2015) Early kick detection and well control decision-making for managed pressure drilling automation. J Nat Gas Sci Eng 7(1):354-366. https://doi.org/10.1016/j.jngse .2015.08.067

Velmurugan N, Bansal G, Sharma T, Gandhi R (2015) WellCON: an early kick detection system. SPE. Paper presented at Abu Dhabi international petroleum exhibition and conference held in Abu Dhabi, UAE, 9-12 November. https://doi.org/10.2118/177670-MS

Zhang Z (2017) Development and characterization of synthetic rocklike materials for drilling and geomechanics experiments. Master thesis, Faculty of Engineering and Applied Science, Memorial University of Newfoundland, St. John's, NL

Publisher's Note Springer Nature remains neutral with regard to jurisdictional claims in published maps and institutional affiliations. 